\title{
Contribució de la literatura popularista dels segles XVIII, XIX i XX a la història toponímica valenciana
}

\author{
Joaquim Martí Mestre \\ Universitat de València. \\ Institut Interuniversitari de Filologia Valenciana \\ joaquin.marti@uv.es
}

Resum: Els autors popularistes generalment pretenien elaborar un model lingüístic que no s'allunyés de la llengua viva, $\mathrm{i}$ això els impulsava a reproduir en els seus textos els topònims i antropònims en la seua forma més popular, de manera que aquests escrits són una font gens menyspreable en l'estudi de l'onomàstica dels darrers segles. En aquest article ens centrarem especialment en els topònims que fan possible l'aportació de noves dades per relació a l'OnCat de Joan Coromines i als diccionaris històrics i etimològics, i, de vegades, permeten matisar o complementar hipòtesis i interpretacions precedents.

Paraules clau: Toponímia històrica; Literatura popularista; Història del lèxic.

\begin{abstract}
The popular authors generally wanted to elaborate a linguistic model who was not separating of the living language, and that stimulated them to reproduce in his texts the toponyms and anthroponyms in his more popular form, so that these writings are a interest source for the study of these words in the last centuries. In this article we want to focus specially on the toponyms that make possible the contribution of new information with relation to the $\mathrm{OnCat}$ and to the historical and etymological dictionaries, and sometimes, they allow to complement and update hypothesis and previous interpretations.
\end{abstract}

Keywords: Historical Toponymy; Popular Literature; Historical Lexicography.

》) Martí Mestre, Joaquim. 2015. "Contribució de la literatura popularista dels segles XVIII, XIX i XX a la història toponímica valenciana”. Quaderns de Filologia: Estudis Lingüistics XX: 271-293. doi: 10.7203/qfilologia.20.7522 



\section{Literatura popularista i toponímia}

Afortunadament, cada vegada tenim un millor coneixement de la ingent producció de literatura popularista que tingué lloc al País Valencià durant els segles XVIII, XIX i primer terç del XX. La voluntat dels autors d'aquests papers de no allunyar-se de la llengua viva els impulsava a reproduir els topònims $i$ antropònims en la seua forma més popular, amb matisos fonètics dialectals i vulgars, recollits segurament de fonts orals de primera mà, sense preocupar-se gaire que concordessen o no amb la tradició documental ni amb les formes oficialesques, sovint castellanitzades ${ }^{1}$.

Ens agradaria en aquesta ocasió reivindicar, amb alguns exemples, l'interés d'aquestes fonts literàries, tradicionalment massa desateses per part dels investigadors, per a l'estudi de la toponímia catalana, centrant-nos especialment en topònims que fan possible l'aportació de noves dades per relació a l'OnCat de Joan Coromines i als diccionaris històrics i etimològics, $\mathrm{i}$, de vegades, permeten matisar o complementar hipòtesis i opinions precedents.

\section{Toponímia major valenciana}

Començarem referint-nos als topònims valencians, especialment a algunes variants formals que trobem en els textos de vocació popular. En un romanç il·licità de 1776 es documenta la variant Almosafes (per Almussafes) (Sansano, 2000: 304). Es tracta d'una variant poc freqüent, no enregistrada en l'OnCat (II, 163) ${ }^{2}$, ni tampoc per part de Barceló (1983: 94), la qual s'uneix als diversos casos de $o$ per $u$ que es troben en valencià. Veny $(2011: 37)$ explica que el contacte amb una $m$ pot fer variar el timbre d'una vocal velar, com ocorre en dumenge / domenge, tant en sentit $o>u$ (morter, murter llatí MORTARIU) com en sentit $u>$ $o($ MURAENA $>$ morena $){ }^{3}$

\footnotetext{
${ }^{1}$ En un altre lloc ens referim al tractament castellanitzant que va patir la toponímia valenciana durant els segles XVIII i XIX en la cartografia i en altres textos geogràfics, i a la vindicació de les formes populars per part dels lexicògrafs valencians del segle XIX (Martí, 2002).

${ }^{2}$ Coromines (OnCat) afirma que Almussafes és l'única pronúncia que té anotada d'aquest topònim.

${ }^{3}$ En altres casos hom parla d'ultracorrecció o dissimilació, especialment davant una $i$ tònica o àtona (cf. Farreny, 1986: 134; id., 2004: 184-185; Schmid, 1988: 35; Colomi-
} 
Arrancapinos és el nom d'una antiga alqueria i partida de l'Horta de València, antic camí i carrer, i avui barriada de la ciutat. En la literatura popularista dels segles XVIII i XIX apareix sempre Arrancapinos, ex. "del camí de Arrancapinos" (Rahonament entre Chimo el Gros del cami de Arrancapinos y el tio Joan Senén de Patraix, 1797, 1), "qu·és mon cosí Montesinos, / que al molí de Arrancapinos / anaba per esta senda" (Llombart, Obres festives, 1876, 119), veg. també Martí (2007b: 111; 2011: 75). Aquesta, juntament amb la variant Rancapinos, és també la forma que documentem als segles XVI i XVII en fonts valencia$n^{4}{ }^{4}$. En cap cas no trobem antigament la forma Arrancapins, que, com diu Coromines (OnCat, II, 249), n'és una valencianització artificiosa. Aquest filòleg s'inclina per un probable "nom mossàrab d'una zona [...] que calgué urbanitzar, desfent-hi un bosquet de pins". Amb tot, no oblidem la presència d'Arrancapinos en altres indrets de la Península Ibèrica, com Aragó, Múrcia, Almeria o Extremadura, a través de la rondallística i la mitologia populars (Martí, 2007b: 111; Martínez, 2012: 452), de la toponímia (Arrancapinos, a Caravaca) (González, García, 1999: 119), i de l'antroponímia (Arrancapinos, malnom a Cella, i a altres indrets), a més de formar part del lèxic espanyol comús, per la qual cosa considerem més factible l'alternativa d'un nom arribat per via aragonesa o castellana.

Es documenta la forma Benatússer (per Benetússer) en alguns textos literaris valencians del segle XIX: "Masanasa y Benatúser" (Discret rahonament, 1802, 6), "Benatúser, Burjasot, / Benimaclet, Campanar" (Josep d'Orga, en Lo Rat Penat 1876, 25), "Què dic? Benatúser!"

na, 1991: 19; Recasens, 1991: 151), o d'assimilació, davant una altra o (Cano, 1995: 40; Giralt, 2012: 40), i altres s'expliquen per fidelitat etimològica (Farreny, 2004: 185; Giralt, 2012: 40). També es troben casos en altres contextos, que semblen apuntar cap a un fenomen més estés en la llengua popular. Per ex. bogada: "Dia de bogà" (Cidon, Les beates, 1909, 7), o cocaracha, en el castellà imperfecte d'un personatge valencianoparlant: "Viquilante! Una cocaracha... ¿La chafo?" (Thous, Hernández, A la vora del riu, mare..., 1919, 15).

${ }^{4}$ Als exemples que citàvem en un altre 1loc (Martí, 2007a), podem afegir-ne aquest, procedent del dietari de Porcar: "Dilluns, a 3 de octubre 1622, morí lo doctor micer Bonavida. [...] Y morí en la sua alqueria de Rancapinos" (CICA: f. 399r, 1. 16).

${ }^{5}$ En Terreros (1781) arrancapinos "hombre muy pequeño", i en el DRAE (des de 1791) "apodo que se aplica al hombre pequeño de cuerpo" (NTLLE). Probablement seguint aquestes definicions, Rosselló (2004: 217, 221) situa el “c. de Arrancapinos” del plànol de Tosca (1704) en el grup dels castellanismes, i el considera format amb un malnom o renom. 
(Llombart, El pare Mulet y Bou solt, 1877, 53), "Mira si he corregut terres / qu·e·stat en Alchemesí, / en Picaña, en Benatúser" (La Traca, 78, 1886, 2). Barceló (1983: 109) documenta Benituçen, Benitucem, Benitosen i Benituça al segle XIII, i Benitucer el 1347. Coromines (OnCat, VII, 208) troba Benetúcer en la Brama dels llauradors de l'Horta, i Benitúcer el $1609^{6}$. En el DCVB es registra Benatússer com a variant formal de Benetússer, però sense documentació, datació ni localització. Sanchis Sivera (1922: 102) arreplegava, juntament amb Benetúser, les var. Benatúser i Benitúser, però també sense documentar-les ni datar-les. Entre els lexicògrafs val. del segle XIX, trobem Benatúser per primera vegada en MGad, com a var. de Benetúser ${ }^{7}$.

L'etimologia del topònim és poc clara. Barceló (1983) planteja la possibilitat d'un origen àrab, però davant les dificultats fonètiques que presenta, no arriba a formular-ne una etimologia concloent, si bé en un altre lloc (Barceló, 2011: 101) el situa entre els topònims àrabs formats amb Beni- (o variants) i el nom propi de l'avantpassat. Per la seua part, Coromines (OnCat, VII, 284-285) pensa a situar-lo entre els diversos topònims romànics amb el component PINNA 'penya' arabitzats com a benna, que es confonen amb l'arabisme Beni. La documentació d'una var. formal com Benatússer, si bé en una data relativament recent, és un element més a tenir en compte en la història etimològica d'aquest topònim, encara d'origen poc transparent.

Documentem als segles XIX i XX les formes populars Benicassi $\mathrm{i}$ Benigani: "ixquérem en lo tren fen cap a Benicasi" (Revista de Castellón, 51, 1914, 4), "S'ha enterat d'eixe accident d'ahir a la carretera de Benicassi?" (Forcada Traver, Les Camiles, 1974, 89); "Benigani, poble de la mare Inés y de la bona confitura, y planter de lliberals nous" ( $E l$ Mole, 1855, 156), "l'arrop / qu·en Benigani es fabrica" (Ensisam de totes herbes, 1891, 34), "li preparen a vosté un atre paraís en Benigani" (Méndez, El tarambana, 1917, 6). Aquestes formes corresponen a la pronúncia popular actual d'aquests topònims (cf. OnCat, III, 302; IV, 311). Encara que en la documentació antiga sol mantenir-s'hi la - $m$ final etimològica ${ }^{8}$, s'hi poden trobar alguns casos sense aquesta consonant,

\footnotetext{
${ }^{6}$ Benetúser es documenta també en el dietari de Porcar, l'any 1612 (CICA, f. 166r, 1. 4). ${ }^{7}$ Abans Escrig (1851) només registra Benetuces, i considera Benetúser com la traducció castellana. En EscLl, juntament amb Benetuces, ja apareix Benetúser com a val.

${ }^{8}$ Aquesta és també la forma recollida generalment pels tractadistes moderns (veg. Martí, 2002: 833-834), i la que ha triomfat com a oficial.
} 
els quals proven la popularitat de la pronúncia amb - $i$ final ja en temps ben reculats, ex. "en les mars de Benicassi, de regne de València" (a. 1415) (Epistolari de Ferran d'Antequera, en CICA, c. 671, 1. 11), "rector de Benigani" (a. 1410) (Tolosa, Company, Aliaga, 2011: 254).

Una altra forma popular que documentem al segle XIX és Berraguart: "el forner de Berraguart" (Rahonament entre el Rull de Payporta y Albudeca, s. a.: 1802, 2), "Pego, Oliva y Berraguart" (Ensisam..., $207)^{9}$. Continua viva actualment, juntament amb Berreguart, que es documenta ja al segle XVI (Labarta, 1987: 181) ${ }^{10}$. El canvi de $e$ pretònica interior a $a$ es pot explicar tant per assimilació a la vocal tònica com per la proximitat de la vibrant ${ }^{11}$.

Apareix la variant Clavillent en una peça teatral alcoiana, per referència a un famós roder crevillentí: "est·és Chaume Clavillent" (Mentres pasa la diana. Esenes alcoyanes, 1855, 15); encara actualment a Alcoi hom recorda la locució, caiguda ja en desús, ser més lladre que Joume Clavillent (Tormo, 1997: 1194). La variant Clavillent figura també en Escrig (1851), que solia arreplegar les formes populars dels topònims.

Es troben les formes aferètiques Gemesí i Girós, per Algemesí i Algirós, respectivament: "Cuant vaches a la Ribera, / no pases pel Chemesi" (Ensisam..., 27), "endur-se'ls [els bous] a traure barques / per lo camí del Chirós" (Corrida de toros del lunes 13 de setiembre de 1831, Bibl. Serrano Morales, ms. 6781, 5), que deuen explicar-se contextualment per confusió de la síl·laba inicial amb l'article masculí. Cf. Albocàsser, popularment lo Bocasse (Sanchis Guarner, 1992: 118), "pel bokáse", "del bokáse", "al bokáse" (OnCat, II, 86).

Normalment la capital del Camp de Morvedre es documenta en els textos populars del segle XIX sota les formes Morvedre i Molvedre, aquesta darrera, originada per dissimilació de les consonants bategants,

\footnotetext{
${ }^{9}$ Abans, "Josef Pellicer de Berraguard" en l'epistolari de Gregori Maians (vol. IV, Mayans a Nebot, 21 d'abril de 1742, en Biblioteca Valenciana Digital).

${ }_{10}$ Juntament amb Bellreguart, Belreguart, Belrreguart, més nombrosos (sobretot els dos darrers), en processos inquisitorials sobre moriscos valencians.

${ }^{11}$ Sobre l'origen etimològic d'aquest topònim saforenc, prou controvertit, podeu veure'n un resum en Garcia Frasquet (2012), el qual, reprenent i actualitzant una vella hipòtesi de Sanchis Guarner, i coincidint amb la interpretació del $D C V B$, s’inclina per considerar-lo un compost de reguard 'mirada' i de l'adj. bell. Les formes Bellreguard, Bellreguart, Belreguart apareixen diverses vegades en un manual de consells de Gandia del darrer quart del segle XV (cf. CICA).
} 
és la més estesa actualment en la llengua popular. En el periòdic $L a$ Traca documentem Moltvedre (a. 1886, n. 65, 1; n. 66, 2), que deu ser una forma ultracorrecta.

El topònim de la ciutat de València el Parterre (El Saltamartí, 3, 1861, 4; La Traca, 61, 1886, 2; id., 125, 1889, 4) es documenta també en les variants Panterre (La Traca, 48, 1885, 3; Hernández Casajuana, El pati dels cañarets, 1914, 15), Pallterre (Llombart, El pare..., 118), Panterri (Bellido, Els quintos de Patraix, Bibl. Municipal de València, ms. MG-39 (8), 3; El Frare, 12, 1895, 4), Parterri (Llibret en la relasió y explicasió de tot lo que conté la falla dels carrers de Lepanto y Doctor Monserrat. Añ 1927, 9), Paterri (Millàs, Una agènsia de criaes, 1874, 10). Les formes amb $n$ i $l l$ deuen explicar-se per dissimilació de les consonants ròtiques, com també Paterri, per dissimilació eliminatòria de la bategant. Quant al canvi de la $e$ final en $i$, es produeix en valencià també en altres mots (cf. Colomina, 1991: 18).

En un sainet de Liern es documenta la forma Malfasar, interessant variant de Massalfassar, explicable per haplologia, si no és una errada: "y ham corregut / Ibi, Albuixech, Malfasar [...]" (Telémaco en l'Albufera, 1868, 23).

La variant Portacèlit, "el convent de Portasèlit" (Liern, La mona de Pascua, 1862, 29), amb la característica epítesi de - $t$ en val. en els mots acabats en -i àtona (gènit, cànvit, càndit, etc.), que veiem ací aplicada també a un topònim.

La variant Xerivella, amb $e$, probablement per assimilació a la vocal tònica, no registrada en el DCVB ni en l'OnCat: "en el poblet de Cherivella" (Lladró, A falta de buenos, 1855, 5), "Cuan u sàpia Cherivella" (id., 14).

Comentem, per acabar aquest apartat, que la forma tradicional i genuïna Alacant és la que es documenta normalment en els textos popularistes valencians dels segles XVIII i XIX, tant en els procedents de les comarques centrals com de les meridionals del país ${ }^{12}$, ex. "Dos bar-

\footnotetext{
${ }^{12}$ A mitjan segle XIX Escrig (1851) dóna com a preferent Alacant, però recull també Alicant, forma que, en efecte, també es pot escoltar actualment en valencià, i en parlants de la primera generació. En els textos catalans antics la forma habitual és Alacant, però Alicant es documenta en alguns textos, com la Primera part de la Història de València (1538) de Beuter, i el Llibre de les grandeses de Tarragona (CICA), tots dos del s. XVI. No creiem que hi haja dubtes sobre la procedència castellana d'aquesta forma, més tenint en compte que en castellà Alicant i Alicante es documenten ja al segle XIII (Rubio
} 
ques grans / dels peixcadors, en més tirs / que lo castell de Alacant" (Coloqui nou en què Tito Bufalampolla y Sento el Formal conten la maestransa..., 1789, 10), "de haber fochit a Alacant" (Coloqui entre el tio Bernat y Saro, 1813, 5), "En Alacant a conte de dir abaixa, diuen deballa" (El Mole, 1837, II, 184-185), "y el c·arreglà les dos prosesons d'Alacant" (L'Ametrallaora carlista, 1, 1871, 3), "un relichós / que el acompañà a Alacant" (Sansano, 2000: 299), "Tot per la glòria / y el interés de Alacant!" (Miquel, Micos y mones, 1888, 31), "Més valguera que te n'anares a la Horta de Alacant a plegar sarmens" (El Cullerot, 4, 1897, 3), "Dihuen que Alacant és / tot un chardinet de flors, / y com les flors tenen cucs, / Alacant en té a pilots" (El Amic del Poble, 5, 1899, 1), i en Bernat i Baldoví (Martí, 2011) ${ }^{13}$. En canvi, en el gentilici és més habitual trobar alicantí, fins i tot en textos on es llegeix Alacant com a topònim: "Ay, paisanes! [...] Recordeu-von de mosatros, de estos alicantins que may olviden a les chiques boniques de Alacant" (El Cullerot, 18, 1897, 1), "Alicantins, pochs y fins. Se referix al caràcter especial dels naturals de la ciutat d'Alacant" (Tipos, modismes y coses rares y curioses de la Terra del Ge, 1908, 11). A banda de la interferència del castellà alicantino, potser la í tònica afavorí la forma alicantí, per assimilació.

\section{Toponímia menor valenciana}

La literatura costumista dels segles XVIII i XIX permet de documentar una sèrie de topònims, menors o locals, difícils de trobar en altres fonts. Per exemple, en la peça teatral d'Escalante i Feo Del porrat de Sent Antoni a les torres de Serrans (1887) s'enumeren pel seu nom els departaments de l'antiga presó de les torres de Serrans de València: "Agrana tota la escala, / corredors, esta saleta; / acabant totes les peses: / la Comuna, la Cañeta, / Peñó, el Cubo ${ }^{14}$, Sent Chuan, / en fi, tot, pesa per pesa" (p. 34).

García, 1981: 13; CORDE), però potser convindria matisar o aclarir una mica l'afirmació categòrica de Coromines (OnCat, II, 52) sobre la inexistència d'Alicant en català.

${ }^{13}$ Rarament trobem Alicant: "el cèlebre Sequa, que morgué prenent el bany en les aigües d'Alicant" (Ribés Pla, Cuadros de costums castellonenchs, 1916, 93).

${ }^{14} \mathrm{Cf}$. "és just que la caritat y almoyna que es recull en les torres de Serrans, així en la cañeta que es trau per la reixa del $C u b o$, com en lo cep o caixeta de la capella de dita torre, sia convertida sens frau algú en aliment y benefici dels pobres presos miserables 
La $O$ de Sant Joan és el nom popular de l'enorme rosetó cegat de l'església de Sant Joan del Mercat de València. El mot $o$, encara que no figura en el $D I E C$ ni en el $D N V^{15}$, té en català el significat de 'rosetó, claraboia', tal com el recull el $D A g(\mathrm{~V}, 224)$, que el documenta en un text de 1509 procedent de la Revista de Girona, i el recull en la $O$ del $P i$, el rosetó de l'església del $\mathrm{Pi}$, de Barcelona. Igualment, el $D C V B$ inclou $o$ 'obertura circular ovalada en una façana, especialment d'església', que registra a la Plana de Vic, Barcelona, Tarragona i València, i a les referències del $D A g$, hi afegeix un document de 1583 procedent de l'Arxiu Municipal de Valls, i el topònim la O de Sant Joan de València, encara que en aquest cas sense aportar-ne documentació.

Trobem el mot $o$ al segle XVII, com a terme arquitectònic, per referència a les esglésies de Sant Martí i de Sant Joan del Mercat de València: "que los dits mestres hajen de desfer la paret que fa tanca damunt lo arch de la capella a hon y à una $o$ " (a. 1621, contracte per a la construcció del campanar de l'església parroquial de Sant Martí, entre electes d'aquesta i els artífexs Bartolomé Abril i Tomàs Leonart) (Pingarrón, 1998: 547), "en la part de la o se han de fer regates de dos pams de alsada y de tota la fondària que es puga" (a. 1693, "Capitulacions de la obra que se ha de fer en la església parrochial de Sant Joan del Mercat de la present ciutat de València") (Pingarrón, 1998: 647), "La $o$ se ha de igualar y masisar per dins la església, paredant-la de algeps y rachola y trabant-la en la paret vella y arquitrau de pedra que està alrededor de la $o$ ab quaranta trabes lo menys de un pam en quadro, picant molt bé, agranant y arruixant la paret vella y arquitrau per a que agarre bé el algeps. Y es tallarà eo llevarà tot lo que resalta el arquitrau de dita $o$, de modo que quede tot igual, deixant en lo mig de dita $o$ una finestra de nou pams y setse de llum" (id., 653) ${ }^{16}$.

de dita presó" (Ordinacions de les presons, València, 1690, p. 10), “qu·en les Torres de Serrans hi à un departament, que li diuen el Cubo, qu·és més roín que una porcatera. Allí estan els presos com a serdos. Qu eixe Cubo, per considerar-lo impropi per a aloixar sers rasionals, en una visita que feu a les torres allà per l'añ 72 el inolvidable $\mathrm{D}$. Amadeo de Saboya, dispongué tapiar-lo. Y que·ls conservaors el utilisen a costa de la salut dels presos" (La Traca, 27, 1885, 3).

${ }^{15}$ L'inclou MGad: $o$ 'ventana circular que se ve encima de la puerta de algunas iglesias y otros edificios'.

${ }^{16}$ Sobre aquesta església, diu Pingarrón (p. 203) que "la edificación sustancial de la fàbrica gótica de la iglesia de los Santos Juanes, determinada al parecer por un primer incendio en 1311, se produce a lo largo del siglo XIV en el tipo de nave única regularizado 
Donava nom popularment al mercat que es feia als peus de l'església de Sant Joan, i on s'establien, entre altres, sabaters, llanterners o cadirers, conegut com la $O$ de Sent Joan, o simplement $l a O^{17}$. Amb aquest sentit el documentem sovint en els textos literaris d'inspiració popular del segle XIX i primer terç del XX, ex. "-Yo tinc hui que arrematar / faena pe a la botiga, / y lo primer que·s traurà... / -A hon té vosté la botiga? / -En la O de Sen Chuan / els dumenches... / -Vacha un / establiment!" (Escalante, Obras dramáticas, II, 57), és sabater; "Y els establiments de sabateria qu·estan en la O de Sen Chuan" (Llombart, El pare..., 116), "Pa casar-se Pep Panchofles / en Quica la Botinflà / comprà un anella de bronse / de la O de Sen Chuan" (La Traca, 31, 1885, 2), "Vinga el cabàs (Va arreplegant calser, y ficant-lo en lo cabàs) / y a la $O$ a fer dinés" (Roig i Civera, Les botigues de la $O, 1885,262$ ), és sabater. "Tres o cuatre cahires, que lo mateix poden ser de Vitòria que de la O de San Chuan" (Fe Castell, Carmela la pentinaora, 1927, 7), "Concheta: -Lo qu·és menester que no se córrega la veu, pués entonses no mos tocarà atre que posar paraeta en la $O$ de San Chuan. Silvestre: -O vendre la colecsió a un anticuari, que ya tinc coses molt boniques. Repara quina més curiosa [...] Una moneda de fa qui sap els añs" (Puig Espert, Lo que ningú sabia, 1928, 41), per les moltes monedes falses que li han donat, "Ho portàrem a vendre als llanternes establerts sota $l a$ $O$ de Sant Joan" (Peralta, 2007: 136). Igualment, la popularitat de la $O$ de Sent Joan la va convertir en inspiració per a locucions populars, per a ponderar la grandària, la redonesa o la manca de lletres (veg. Martí, 2011, s. v. lletra).

\section{Topònims valencians en unitats fraseològiques}

Enllaçant amb això, convé no oblidar que en la literatura popularista resulta relativament freqüent de trobar topònims, i antropònims, formant part d'unitats fraseològiques. Si ens limitem a les no registrades en el $D C V B$, podem citar-ne, com a mostra, per exemple, la locució estar entre Ares i Benassal: "Parlant, parlant, agarrà 1 barral lo sinyó Nelo, que ya estaba entre Ares y Benasal" (Revista de Castellón, 54, 1914,

con los elementos típicos, incluyendo el rosetón a los pies más impresionante de templo alguno en València: la 'O' de San Juan, semitabicado en la transformación barroca”. ${ }^{17}$ Als baixos de l'església de Sant Joan de València es trobaven les tendetes o casetes de Sent Joan, ocupades pels llanterners (cf. Llorente, 2011: II, 73). 
2), usada, a les comarques castellonenques, per assenyalar que algú està mig embriac ${ }^{18}$. La idea d'estar mig borratxo la veiem expressada en valencià amb altres locucions que contenen el concepte de meitat, com portar mitja punta (o mitja punteta), anar a mitja vela, o estar a mig $v i$, o borratxet a mig vi, que apareixen en la literatura popularista dels segles XVIII, XIX i XX:

"Bufanda: -Ama de llaves, Carcaixent, mundo, figuera, auto... Me pense, siñor Llongo, que vosté porta micha punteta suau. Drapero: -Con que micha punta, eh? Arrepare lo que li porte" (Hernández Casajuana, ¡Eh, la beta!, 15), "Però si creus que la chent / se'n torna mústia, t'engañes, / pués tots van a micha vela, / fent-los els ulls patarates, / y en la gran satisfacsió / de que la mona es mencharen" (E. Escalante, en $L a$ Traca, 69, 1886, 3), "Les festes anaven transcurrint com tots los anys. Els fadrins passaven la semana a mig vi, quan no a tot. I quants destarifos feen!" (Pascual Tirado, 1935: 127), "Vosatros, pobres fajendes, no teniu més ànima que per a veure un got de vi en casa Peluca. Después eixiu de allí contant el pa y la cansarrarra, borrajets a mig vi, y aneu fent por en navaixetes" (Junta secreta, 1787, 6).

Els topònims més populars solen ser una bona font d'inspiració per als fraseologismes. Així ocorre amb Micalet, nom popular del campanar de la Seu de València: alt com un Micalet, gran com lo Micalet, més gran que el Micalet, en més anys que el Micalet, tindre més anys que el Micalet o més vell que el Micalet, més fort que el Micalet, més llarg que el Micalet de la Seu, més sério que el Micalet, més templat que el Micalet, més valencià que el Micalet, o mirar (una persona o una cosa) més alta que el Micalet 'veure-la fora del seu abast', que trobem en diversos textos valencians de l'època:

"Y molt gran, / alta com un Micalet" (Rahonament entre Chimo el Gros..., 4), l'estàtua del Colós de Rodes, "Al veure els chagants y nanos / no menor goitg em causà. / [...] Que creixcuts, y que elevats! / La Giralda de Sevilla / no es pot ab ells comparar. / Eren com lo Micalet, / eren llarchs com lo mal any, / y eren redons com un bolo / o com la $\mathrm{O}$ de Sanct Juan" (a. 1730) (Furió, 2001: 147), "ràbens com el Micalet, /

\footnotetext{
${ }^{18}$ Querol (1995: 122) recull la locució estar entre Ares i Benassal "per a indicar una qualitat o posició intermèdia”, i Serra i Fortuño (1995: 133) diu que es coneix a Castelló amb el significat d'“estar dubtós, a meitat camí de trobar la solució'.
} 
tendres que's deixen menchar" (Joan B. Gómez, Coloqui entre Goriet y la Chora, s. a., 2), "té ya preparà per a l'obchecte una tortà com el Micalet de la Seu" (Llombart, El pare Mulet y Bou solt, 1877, 93), "s'ha de fer un alambic / com lo Micalet de gran" (Coloqui entre el tio Bernat y Saro, 1813, 1), "Che, que gràsia!... Corredor, / en més añs que·l Micalet" (Alberola, Mosén Ramon, 1928, 6), "qu.ha de puchar esta escala / més alta que · Micalet" (Llombart, Cebrián, La sombra de Carracuca, 1876, 12), "Pepe, un chicarron més alt que $\cdot$ l Micalet y més gros qu·un bòlido" (Barchino, ¡Che, que chenteta!, 1916, 775), "Ben feta de cap a cap, / més forta que el Micalet" (Brown, Escartí, 1990: 80), "(Per a tindre-la contenta, / l'ha de estar sempre alabant, / però aixina que me case, / li fas una creu més gran / que $\cdot$ l Micalet de la Seu)" (Millàs, Retratos al viu, 1884, 11), a la sogra, "-Diga, y qu·és una aspindarga? / -Una escopeta més llarga / que·l Micalet de la Seu" (Liern, La toma de Tetuán, 1861, 9), "en unes fitores més llargues que el Micalet..." (Costa, Amparito Porselana, 1931, 8), "S'ha quedat / més sério que.l Micalet" (Palanca, Decrets de la providènsia, 1878, 64), "el tirà sa mare al món, / més templat que-l Micalet" (P. Peycé, en Llombart, Tipos d'auca, 1878, 121), "Estem molt agraïts al bon recort que mos dedica este gran artiste, que des de Madrit, és tan valencià com el Micalet" (El Buñol, 5, 1928, 9), "-Y el paperet? / -Tututú! / Eixe paper és més vell / que el Micalet" (Vives, Entre amics no cal tovalles, 1877, 22), "Si és més vell... que·l Micalet" (Alberola, L'amo y señor, 1927, 69), "Té mal pesar! / Des de hui el tinc que mirar / molt més alt que·l Micalet" (Escalante i Feo, Cada u de son temple, 1890, 19), diu Huiso, desentenent-se del seu germà Ramon, molt fanfarró, amb qui sempre està discutint, "Yo promet qu·esta saleta / la tinc que mirar més alta / que ·l Micalet" (Escalante, Obras dramáticas, II, 184), diu la sogra, decidida a no tornar-hi, a molestar la filla i el gendre, "Tu, Salvaor, pots endur-te a Rafael y fer d'ell lo que te done la gana, y esta casa des de hui la mireu més alta que ll Micalet" (Montesinos, Un Belmonte de sotana, 1917b, 12), despatxant-los de sa casa.

El $D C V B$ recull a València, sense documentar, el refrany poquet a poquet va l'aigua al canet, el qual "vol dir que les coses no s'han de fer precipitadament sinó amb calma i esperant que arribi llur bon temps". El documentem a mitjam segle XIX: "Pareix que el Achuntament ha deprés de memòria les beseroles munisipals d'El Mole. La cosa ya va bé en los teatros. Poquet a poquet va l'aigua al canet. A-spayetet, aspayetet" (El Mole, 1855, 189), amb la variant aspaietet aspaietet va (o aplega) l'aigua al canet: "No corre presa. Aspayetet, aspayetet, va 
l'aigua al canet" (El Mole, 1855, 234), "que aspayetet, aspayetet, aplega l'aigua al canet" (id., 1864, 250). Format sobre canet, dim. de cano, mot relacionat amb la conducció d'aigües (cf. DECat, II, 475-477) ${ }^{19}$. Uns anys més tard el llegim amb el nom de lloc Canet: "Aixina, poquet a poquet, com va l'aigua a Canet, anaven los dos, mirant a terra y arrastrant los peus per lo pes dels anys" (Revista de Castellón, 54, 1914, 1), “com poquet a poquet va l'aigua a Canet, sense que ell se n'adone, assí faran cap a la curta o a la llerga" (Almanaque Las Provincias 1924, 310 ), expressant que, encara que a poc a poc, acaba ocorrent un fet $^{20}$. L'atracció o confusió entre els homònims canet (nom comú) i Canet (topònim $)^{21}$ explica la doble possibilitat de construcció de la parèmia ${ }^{22}$.

El DCVB registra en valencià, sense documentar-lo, l'enunciat fraseològic Catarroja descuberta!, que "es diu quan algú ha descobert el Mediterrani”. El documentem també per expressar que s'ha descobert una cosa oculta o desconeguda, i no únicament per referència a les coses que hom creu descobrir i ja eren ben conegudes (veg. Martí, 2011). Un sentit semblant té l'enunciat paronímic terra roja descuberta!, no registrat en el $D C V B$, que trobem en textos del segle XIX i del darrer quart del XVIII procedents de l'àrea del català central, i que, tant per la semblança formal com pel significat, cal relacionar amb l'anterior, la qual cosa ens obre la porta al camp escassament tractat de la variació i de la correspondència diatòpica en les unitats fraseològuiques dins una mateixa llengua; per ex. "No·t fies de la criada, / y, de fiar-te, està certa / que a la millor ocasió / terra roja descuberta" (El Sarrabal de la ciudad de Barcelona para el año de 1792, p. 26), "Ramona: -Què·n sabs? / Vi-

\footnotetext{
${ }^{19}$ En el $D C V B$ s'inclou aquest refrany en l'article canet 'ca petit o jove', 'belitre o cadell de la sínia' (mall. i eiv.), entre altres accepcions, però pensem que cal considerar-lo més aviat un diminutiu de cano. En EscLl cano 'caño o conducto subterráneo', cano per a detíndrer l'aygua 'esclusa, tapadera' i cano per a péndrer aygua 'compuerta'. Tot i que Coromines (DECat; OnCat, III, 242-243) interprete cano com un mot d'origen mossàrab, el fet de ser conegut també en terres aragoneses (veg. Martí, 2007a: 92-93) ens fa pensar que més aviat deu haver-nos arribat per aquesta via.

${ }^{20}$ També l'hem sentit amb la forma Xanet, xanet va l'aigua a Canet.

${ }^{21} \mathrm{Hi}$ ha diferents indrets d'aquest nom. En terres valencianes es troben les poblacions Canet de Berenguer i Canet lo Roig; a Castelló la dita tòpica Poquet a poquet va l'aigua a Canet. I tan a poquet anave que mai regave deu fer referència, segons Sanchis Guarner (1992: 164), a la partida rural d'aquest nom del terme de la capital de la Plana. ${ }^{22}$ Canet es troba també en la parèmia poquet a poquet arribarem (o anirem) a Canet, que, afavorida per la rima, es ben coneguda en terres valencianes.
} 
centa: -Segons crech, és una pessa / que si fos d'or... / Ramona: -Sí, vols dir? / Vicenta: -An Nofre sopant me deya..., / com ell des de la barraca / tot ho veu, que a la escaleta / hi ha molt tràfech; també dihuen / si té l'home fora, a Lleida; / no·t vaig a dir altre cosa: / Figura't qui serà ella, / cuant de la castellanota / del sach d'orgull és parenta. / Ramona: -Sí, sí, vamos, no hi ha dupte, / terra roja descuberta" (Dimas, Cap geperut se veu lo peix, 1862, 12), criticant una veïna.

\section{Adaptacions de topònims de fora del País Valencià}

A continuació ens referirem a les adaptacions de topònims forasters. Resulten especialment interessants aquelles formes que no han triomfat en la llengua normativa moderna, però que devien ser populars a l'època dels nostres textos, $\mathrm{i}$ en alguns casos encara ho són actualment. Aquestes adaptacions ens informen també sobre processos fonètics populars.

Una d'aquestes formes és la variant Auropa, per Europa: "puix ha trastornat l'Auropa / de l'un cap a l'atre cap" (Branchat, Conversasió que tingueren el tio Bernat... y Miquelo el Tosut, Bibl. Univ. de València, ms. 1661, 78), "ni tota Auropa" (El Mole, 1837, I, 192), "y si no·s fa·ixò, asò no·s diu Gobern, sinó desgobern, así en tota l'Auropa del món" (id., 234), “encara que l'Auropa s'asole" (id., 248), “eres d'Auropa lo hermós" (Merelo, Els sufriments de Toneta, 1864, 6). Darrere d'aquest canvi pot trobar-se la tendència del cat. occid. a l'obertura d'una $e$ àtona inicial en $a$. És també ben possible que el context amb article (la Europa $>$ l'Auropa) ${ }^{23}$, i en general els contextos on va precedit d'una a (tota Europa > tota Auropa), n'afavorisquen el canvi, per assimilació al timbre d'aquesta, o per una afèresi contextual de la vocal inicial del topònim (cf. l'acuit > la cuit, a acuit > a cuit, Veny, 2011: 170), segurament després d'haver-se canviat en $a$.

Tot indica que cal considerar la forma Gropa, que documentem al segle XIX, sempre precedida d'article, la Gropa, com una altra variant vulgar d'Europa ${ }^{24}$. Aquesta variant deu explicar-se a partir de l'afè-

\footnotetext{
${ }^{23}$ No és estrany trobar el topònim Europa precedit d'article en català antic. En el CICA se'n troben diversos exemples del segle XVI. En els textos popularistes val. del s. XIX trobem tant Europa com la Europa.

${ }^{24}$ Descartem que es tracte del nom comú gropa, perquè en els textos populars valencians del segle XIX consultats aquest substantiu sempre apareix sota la variant grupa
} 
resi contextual descrita anteriorment ([lawrópa]), l'epèntesi posterior d'una consonant velar homorgànica amb la [w] (*[lagwrópa]) i finalment síncope de la $[\mathrm{w}]$ en contacte amb la consonant velar (cf. la oruga $>$ *la guruga > la gruga). L'atracció paronímica del substantiu gropa o grupa pogué afavorir-ne el canvi. Ex. "Palo, pués, y més palo, y ya debia haber do-sents mil hòmens dins de Portugaliño, [...], y en seguideta se menecharien els inglesiños per Seuta, o per Maó, o per Canàries o Felipines, [...] y els fransesets y els rusos els calfarien les costelles [...], y la dansa de tota la Gropa del món ${ }^{25}$ encomensaria en Portugaliño" (El Mole, 1840-41, I, 232), "El eixèrsit és indispensable baix tots conseptes, tant per rahó de l'estat en què s'encontren la anarquia española y els carlistes com per rahó de l'estat en què s'encontra tota la Gropa del món" (id., 1870, 82), "Cuando un alcalde respire / deu callar tota la Gropa" (Palanca, Suspirs y llàgrimes, 1860, 9), "estant el trono destronat y rebuchat per tota la Gropa com un chavo llanderol" (El Mole, 1870, 114), "Pos així ho han declarat / tots los sàbios de la Gropa" (Ovara, Males llengües, 1879, 11), "me he encontrat en una dona / que venia de llavar, / y me ha dit que al safareig / una dona li ha contat / que la armada dels fransesos / esta més rica y pujant / que totes les de la Gropa" (Llorens Sala, Poesías, 1895, 60-61).

Al segle XIX el nom de la capital biscaina es documenta sovint amb la forma Bilbau, explicable per la preferència pels diftongs sobre els hiats, ex. "als de Bilbau" (El Mole, 1837, I, 72), "Espartero ya s'àrretirat a Bilbau" (id., 278), "és menester posar una rechènsia en Bilbau que no siga boba" (id., 1840-41, I, 71), "com ho veem en Córdoba, Burgos, Bilbau y atres pobles" (Coloqui entre un capador de la Gascunya y un sabater remendó de València, 1808, 2). Aquesta és també la forma que recullen els diccionaris valencians del s. XIX (Escrig, EscLl i $M G a d)$. Compta ja amb documentació medieval en cat., del segle XV (DCVB; Salicrú, 1999: 213).

Una altra adaptació popular és Cais: "Poro no hu dec marmolar, / que, si el vech, serà de sort, / qu·ha estat en Cais a la mort / en l'hospital

(veg. Martí, 2011), que és també l'única forma que recullen els diccionaris d'Escrig (1851), EscLl i MGad (encara que Sanelo arreplegava gropa).

${ }^{25}$ Com podem veure més amunt, l'expressió “tota la Gropa del món” apareix també en aquesta mateixa publicació amb Auropa: “tota l'Auropa del món”. També es documenta amb Espanya: "és mi nóvio, so marqués; / el més templat y més tiés / que hi ha en la Gropa d'España”' (Martínez Vercher, 1865: 19). 
militar" (Balader, Misèria y compañia, 1872, 15), que es correspon amb la pronunciació andalusa popular del topònim. És també l'única forma que recullen Escrig (1851) i EscLl (aquest com a vulgar) (Càhiç), i en MGad juntament amb Càdiç.

La ciutat xinesa de Canton és adaptada com Cantó, i el topònim bíblic Canaan en Canà, seguint, respectivament, les correspondències cast. -ón / cat. -ó (camión / camió, trombón / trombó, etc.) i -án / -à (titán / tità, azafrán / safrà, etc.): "Dos ofisials chinos maltrataren als superintendent y al negosiants inglesos de Cantó" (El Mole, 1840, I, 110), "en les bodes de Canà" (El Sueco, 1859, 34).

Pot resultar també d'interés la forma aferètica Gito, per Egipte: “y totes les plagues de Gito" (El Mole, 1837, II, 39), amb simplificació, a més a més, del grup consonàntic interior. També hi ha afèresi en la variant les Mèriques: "Después de la conquista de les Mèriques" (El Mole, 1837, I, 287), "la flota de les Mèriques" (id., 1840-41, I, 221), "dos frares venguts de les Mèriques" (id., 1855, 189).

La ciutat anglesa de Liverpool apareix adaptada en Llibrepol i en Levrepul, amb metàtesi de la $r$ i palatalització de la $L$-: "Ni en Valènsia, ni en Ruzafa, / ni en París ni·n Llibrepol" (Palanca, En lo mercat de València, Bibl. Nacional, ms. 14158-6, 131), "la porten a la subasta / de Londres o Levrepul, / o cuansevol atra plasa" (Peris Fuentes, El porrat, 1892, 6), la taronja.

Igualment, el nom de la capital portuguesa es troba algunes vegades palatalitzat, seguint el tractament popular català de la $l$ - inicial: "de Llisboa de Portugal" (El Mole, 1840-41, I, 62), "per Llisboa" (id., 63); altres vegades es canvia, per homonimització formal jocosa, en Lisboba i Lixboba: "sortí des de Lisboba en direcció a Barcelona" (Barberà Martí, Assamblea Valencianista, 1908, 92), i Martí (2011). També hi ha adaptació palatal de la $L$ - inicial en Llondres: "bufant un ventet de París a lo llarc de Viena y Llondres" (El Mole, 1870, 114).

El topònim Màlega manté habitualment al segle XIX la $e$, resultat regular en català de la $a$ interior posttònica (cf. Martí, 1994: 79-80), ex. "dels siñors diputats per Màlega" (El Mole, 1837, I, 22), "Era de Màlega y grosa" (Faubel, Mora, El senserró de Moncà, 1872: 6), "al bochí de Màlega" (Palanca, El capital y el treball, 1885, 46), "Què diran vostés que apareix en Màlega?” (La Traca, 33, 1885, 1).

Hi ha simplificació vocàlica i eliminació de la $h$ en Sara, per Sàhara: "Asò més que barberia / pareix el desert de Sara" (Fuster, El nano 
de la falla, 1894, 12), perquè està deserta, "Allà en el desert de Sara" (El Cullerot, 24, 1898, 2), "Remembrances marroquís en les brusentes cendres del desert de Sara! (Ribés Pla, Cuadros..., 95).

En el DCVB s'afirma que "la gent pronuncia Moscu" el topònim Moscou, però el que trobem regularment en els textos valencians de vocació popular del segle XIX i primeres dècades del XX és Moscou: "San Petersburgo y Moscou" (El Mole, 1855, 85), "en la guerra de Moscou o Mospica" (id., 1864, 247), "si no vols que n'arme una com en Moscou" (Sendín Galiana, Tonica la del llunar, 1926, 12), que és també l'única forma recollida per $M G a d$, la qual devia ser llavors la forma popular $\mathrm{d}$ 'aquest topònim en valencià.

Altres adaptacions que documentem en els nostres textos són: Despenyagossos: "Els andalusos ya callen: ya no van a Despeñagosos, ni volen posar siti a Madrit" (El Mole, 1837, I, 155), Gibaltar: "el estred de Gibaltar" (Coloqui de Durango, Bibl. Serrano Morales, ms. 6781, 4), "que parlen de Chibaltar" (Coloqui de la gaceta de Chibaltar, Bibl. Serrano Morales, ms. 6781, 1), "en el siti de Chibaltar" (El Mole, 1855, 221), amb dissimilació elminatòria de les consonants ròtiques; Paquín: "Voldré a Nelo dins de Fransa, / dins de Pakín, dins de Rúsia" (Merelo, Els sufriments..., 22); Senagal: "No pasem al Senagal, / no a Guinea" (Diàlogo reflexiu entre dos amics de la veritat..., 1827, 4), possiblement per assimilació a la vocal tònica; i Tiruel: "ya érem des de chicotets / amantes de Tiruel" (Palanca, Un casament en Picaña, 1859, 19), "Enchamai tant se volgueren / els amantes de Tiruel" (Marçal, Els amants d'Alboraya, Bibl. Nacional, 1862, ms. 14231-10, 23v), amb dissimilació.

Darrere de les adaptacions de topònims podem trobar informacions sobre l'estat de determinats processos fonètics. En un sainet d'Eduard Escalante i Feo el personatge de Blay adapta el topònim Savoia, per etimologia popular, en Sebolla, però el seu interlocutor, Nelo, el corregeix, i li diu que és Seboya:

"Nelo: -Però el curà / y tingué que servir. / Blay: -Chust, / en el rechiment de la / Sebolla. / Nelo: -Seboya, borruch. / Fransisqueta: -Ya m'has fet posar en punches" (Quintos y reganchaors, 1889, 24).

Interpretem que Blay confon la pronunciació correcta del topònim no perquè siga ieista sinó que, com es tracta d'un nom estranger, poc conegut, l'ha malinterpretat per homonimització amb el castellà cebo- 
lla: La diferència entre els sons representats per $l l$ i per $y$ és pertinent per als interlocutors, i per això Nelo el corregeix. Amb això podem observar que el ieisme no etimològic, avui prou estés en l'àrea del valencià central, hi devia ser encara un fenomen inusual al darrer quart del segle XIX, i hom hi diferenciava perfectament entre la $/ \lambda / \mathrm{i}$ la $/ \mathrm{j} /$.

\section{Genèrics toponímics}

Per últim, presenten interés per a la història de la llengua alguns noms comuns associats a topònims que trobem en els nostres textos. És el cas del subst. partida (en pl. partides). Segons el DECat (VI, 311), partida "en català antic té sovint en plural el paper de "paratge, encontrada"; amb aquest sentit el documenta també el $D C V B$, 'regió, contrada': "Remembra les partides de levant en les quals presés mort e passió", Llull Cont. 148, 8. "Armà una nau et dues galees per entrar en córs en les partides de Barberia", Jaume I, Cròn. 92. "Anar a caça de porch en les partides del monastir”, Pere IV, Cròn. 119. D'altra banda, en singular, partida, designa "una porció considerable del terme rural d'un poble" (DECat); en el $D C V B$ 'porció de terreny d'alguna extensió i designada amb un mateix nom', que registra també el $D I E C$, com a terme del dret: 'porció de terreny d'alguna extensió i designada amb un mateix nom, part del terme pertanyent a un poble'.

En els textos popularistes valencians del segle XIX i del primer terç del XX es documenta partida en plural (partides) per referència a un paratge urbà, identificable amb un barri o districte municipal. Cal, per tant, relacionar-lo amb el sentit de 'regió, contrada', que els diccionaris històrics recullen com a antiquat, amb exemples només medievals, però ara inclòs dins l'àmbit d'un nucli de població. Vegem-ne alguns exemples, per referència a barris o districtes de la ciutat de València: "A Valènsia / me l'amporte en un viache. / La fique per los carrers / de les partides del Carme, / y es pert" (Roig i Civera, El tesor dels Chermanells, 1884, 38), "Replanell de casa de veïnat en lo carreró de... en les partides del Pilar" (Soler Peris, La casa misteriosa, 1917, 3), "no trobant habitasió / ni en les partides de Cuart, / Rusafa, Gràsia, Sen Bult, / Carmen, Molvedre y Pilar" (Llibret de la falla dels carrers San Bult y Conde Montornés, 1921, 4), "L'acsió del primer cuadro en un carreró de les partides del Pilar" (Barchino, "La Java", 1925, 4), "del carrer de Molvedre / a les partides de Cuart, / y des de así has- 
ta Rusafa, / y de Rusafa a Serrans, / només que diguen Pepico, / no és menester preguntar" (Falla del carrer de la Correcheria. 1926, 7), "Estem en una planta baixa de la plaseta de... allà en les partides del Carme" (Hernández Casajuana, L'airet de la matinà, 1926, 3), "Tres carrers al fondo y dos cantoneres, formen una replaseta com una anou, en un bàrrio populós de les partides de Rusafa" (Soler Peris, La festa del trevall, 1926, 3).

Als segles XVIII, XIX i principis del XX documentem el subst. vallada per referència al topònim de la ciutat de València Vallada de Sant Francesc, que designava un antic carrer en pendent que conduïa a l'antiga plaça i convent de Sant Francesc, on a les primeres dècades del segle XX es va alçar l'actual plaça de l'Ajuntament. Exs. "un cadirer que havia / Ballada de Sent Francés" (Martí, 1997: 359), "per los Porgets, / Taberna Roja, Beltran, / Ballada de Sen Francés, / la Llonja, casa Peluca" (Parranda y Bufalampolla vénen del norte, cridats de Cento y Tito, 1811, 7), "El teatro representa el prinsipi de la Ballà de Sen Fransés" (Palanca, La Ballà de Sen Fransés, 1868, 9), “D’este món tan gran com és / és lo més bo y agradós, / lo més simpàtic y hermós / la Ballà de Sant Fransés" (La Ballà de Sant Fransés, 1, 1900, 1); i era també coneguda rònegament com la Vallada, per antonomàsia: "si és sastresa / de la Ballà" (Escalante, Obras dramáticas, I, 290), "uns vehins tan incheniosos / com són los d'esta Vallà, / carrer que s'endú la palma / de tots els de la siutat: / Bons valensians, són festeros, / y no hi à qui·ls fique mà / per a·rmar un rebombori / en manco que canta un gall" (Llibret de la falla de la Vallà de San Fransés. 1903, 5-6). Es documenta ja a la primera meitat del segle XVI, en la descripció del perímetre antic de la ciutat de València que fa Beuter: "Era, dons, lo vogi de la ciutat prenent de la torre del Temple que huy és, y anant per les espatles del trinquet de Cavallers a la Confraria de la Verge Maria y de allí als Santets. De aquí anava seguint lo vall fins a l'Estudi General, y de allí, girant per la Morera, tirava per lo carrer de les Barques, a la vallada de Sanct Francés. De allí pujava per la plaça dels Caixers a la Boatella y als Manyans" (CICA: "Història", p. 185, 1. 20). El substantiu vallada es troba també aplicat a altres indrets. Així el llegim en el Dietari de Porcar: "Y arribà l'aygua fins a la vora de la pedra de la Trinitat, y fins a les finestres de l'hort de don Berenguer Aguilar, a la vallada del pont de Serrans" (a. 1589) (CICA: f. 3r, 1. 21). 
A pesar de la presència històrica en valencià de vallada com a sinònim de davallada o baixada, documentat fins a dates relativament recents, no figura amb aquest sentit en els diccionaris històrics i etimològics. En el $D C V B$ es registra vallada 'vall molt extensa', a la Terra Alta i la Ribera d'Ebre; en el DAg (VIII, 179) vallada 'vall, clot entre muntanyes', a Tortosa; i el DECat (IX, 30), que inclou vallada entre els derivats de vall, recull la informació del $D A g$, i diu que és un "col·lectiu usual a les terres de l'Ebre", per a designar un "clot entre muntanyes", tot afegint-hi que "a Mora la Nova designa especialment un fondal llarg i poc fondo". En canvi, sí que el recullen els diccionaris valencians del segle XIX. En Escrig (1851) ballà, da V. baixà, ada, juntament amb aballà V. abaixà; en EscLl ballà, da. Bajada. Lo mismo que baixà, da; aballà, da, y abaixà, da, i en MGad ballà, da. Bajada. V. baixà; aballà, da V. abaixà, da; avallà, da. Bajada. V. abaixà, da.

La forma vallada deu haver-se format a partir del subst. avallada (der. d'avallar, que, al seu torn, es formà sobre avall), per afèresi contextual de la vocal inicial, precedida d'una altra $a$, especialment de la vocal de l'article femení (la avallada, una avallada > la / una vallada) ${ }^{26}$. D'altra banda, la influència analògica de baixada (der. de baixar), amb el correlat abaixada (der. d'abaixar), pogué afavorir la forma vallada (que comptava amb els correlats avallada i davallada / devallada), a pesar de no existir un verb *vallar. El predomini gràfic de ballada, amb $b$-, en els textos valencians dels segles XVIII i XIX obeeix al betacisme

\footnotetext{
${ }^{26}$ Tot i que Coromines (DECat, IX, 31) afirma que "en avançar l'Edat Mitjana", s'eliminà la variant avallar, en favor de davallar, tanmateix llegim avallar en Carles Ros: "Lluch y Blay són dos llauradors de les montanyes que aballaren a València" (Coloqui entretengut hon se referixen les dances, misteris y altres coses tocants a la gran festa del Corpus, València, 1759, 1), i encara a finals del segle XIX en Martí Gadea: "tentat astic d'avallar-me'n de la trona ansense acabar lo sermó, al vore lo poc fruyt que·s trau de vosatros" (Ensisam, 506), i, així mateix, els diccionaris valencians del segle XIX recullen el subst. avallada (aballada) i el verb avallar (aballar) (Escrig, EscLl, MGad), $\mathrm{i}$, com hem vist més amunt, els primers exemples de vallada es troben ja a la primera meitat del segle XVI. Una formació a partir de davallada, per haplologia, podria ser viable sobre el paper, tenint en compte a més a més el caràcter feble de la $d$ - en restar en posició intervocàlica per fonètica sintàctica (la davallada, una davallada), però s'hi oposa el fet que les formes que es troben habitualment en valencià, tant antic com actual, són devallar i devallada, amb de- (cf. DECat, IX, 31-35; CICA).
} 
característic del val. central, afavorit en aquest cas possiblement pel subst. ballada 'acte de ballar' ${ }^{27}$, i potser també per la $b$ - de baixada.

\section{Bibliografia}

Barceló, C. 1983. Toponímia aràbiga del País Valencià. València: IFV.

Barceló, C. 2011. Árab i català: contactes $i$ contrastos. València/Barcelona: IIFV/PAM.

Brown, K. \& Escartí, V. J. 1990. Edició i estudi d'alguns poemes catalans en un manuscrit de don Francesc de la Torre i Sebil. Caplletra 9: 59-117.

Cano Ivorra, M. A. 1995. El Llibre del Mostassaf d'Elx. Edició crítica i estudi lingüistic. Alacant: Institut de Cultura "Juan Gil-Albert".

CICA = Corpus Informatitzat del Català Antic (2009), J. Torruella (dir.), junt amb M. Pérez Saldanya i J. Martines. http://lexicon.uab.cat/cica [Accés desembre 2014].

Colomina, J. 1991. El valencià de la Marina Baixa. València: Generalitat Valenciana.

CORDE $=$ Real Academia Española: Banco de datos (CORDE). Corpus diacrónico del español. http://www.rae.es [Accés novembre 2014].

DAg = Aguiló, M. 1917-1934. Diccionari Aguiló. Barcelona: Institut d'Estudis Catalans (8 vol.).

DCVB $=$ Alcover, A. M. \& Moll, F. de B. 1988. Diccionari Català-ValenciàBalear. Palma de Mallorca: Moll (10 vol.).

DECat $=$ Coromines, J. 1980-2002. Diccionari etimològic i complementari de la llengua catalana. Barcelona: Curial (10 vol.).

EscLl = Escrig, J. \& Llombart, C. 1887. Diccionario valenciano-castellano. València: Pascual Aguilar.

Escrig, J. 1851. Diccionario valenciano-castellano. València: Ferrer de Orga.

Farreny, M. D. 1986. Processos de crims del segle XV a Lleida: Transcripció $i$ estudi lingüístic. Lleida: Institut d'Estudis Ilerdencs.

Farreny, M. D. 2004. La llengua dels processos de crims a la Lleida del segle XVI. Barcelona: Institut d'Estudis Catalans.

Furió, J. M. 2001. Els poemes valencians de Josep Vicent Ortí. Estudi i edició. Caplletra 18: 115-150.

Garcia Frasquet, G. 2012. Els topònims saforencs de la mirada: Bellreguard, Guardamar i Miramar. A Actes de la V Jornada d'Onomàstica. València: Publicacions de l'Acadèmia Valenciana de la Llengua, 251-258.

\footnotetext{
${ }^{27}$ En Carles Ros llegim: "D'así a tres mesos tenim en lo meu poble festa grossa: hi à corregudes y ballades" (Paper graciós, 1745, p. 2).
} 
Giralt Latorre, J. 2012. La llengua catalana en documentació notarial del segle XVI d'Albelda (Osca). Huesca: Ayuntamiento de Albelda.

González Blanco, A. \& García García, I. 1999. Repertorio alfabético de la toponimia de la Región de Murcia. Murcia: ed. KR.

Labarta, A. 1987. La onomástica de los moriscos valencianos. Madrid: CSIC. Llorente Falcó, T. 2001. Memorias de un setentón. Valencia: F. Doménech.

Martí, J. 1994. El Libre de Antiquitats de la Seu de València. Estudi i edició. València/Barcelona: IUFV/PAM.

Martí, J. 1997. Literatura de canya i cordell al País Valencià. València: Denes. Martí, J. 2002. La toponímia valenciana en el diccionari de Josep Escrig (1851). A Casanova, E. \& Rosselló, V. M. (ed.) Congrés Internacional de Toponímia i Onomàstica Catalanes. València: Universitat de València/Denes, 823-842.

Martí, J. 2007a. Afinitats lèxiques catalanoaragoneses en la toponímia valenciana de frontera i la seua projecció en terres aragoneses. Alazet 19: 85-115.

Martí, J. 2007b. La toponímia valenciana en el Llibre de murs e valls (1675) de Josep Llop. Societat d'Onomàstica. Butlletí interior 106-107: 110-117.

Martí, J. 2011. Diccionari de Josep Bernat i Baldoví. València: Denes.

Martínez García, A. M. 2012. Cuentos de transmisión oral del Levante almeriense. Almería: Universidad de Almería.

MGad = Martí Gadea, J. 1891. Diccionario general valenciano-castellano. València: José Canales Romà.

NTLLE = Real Academia Española: Nuevo Tesoro Lexicográfico de la Lengua Española. http://ntlle.rae.es/ntlle/SrvltGUILoginNtlle [Accés novembre 2014].

OnCat $=$ Coromines, J. 1994-1997. Onomasticon Cataloniae. Barcelona: Curial (8 vol.).

Pascual Tirado, J. 1935. De la mena garbera. Castelló de la Plana: Societat Castellonenca de Cultura.

Peralta, R. (ed.). 2007. Gori Muñoz, Ni en cap mapa, ni en cap història y otros escritos. València: Universitat de València.

Pingarrón, F. 1998. Arquitectura religiosa del siglo XVII en la ciudad de Valencia. València: Ajuntament de València.

Querol, E. 1995. Llengua. A La comarca dels Ports. Barcelona: PAM, 115124.

Recasens, D. 1991. Fonètica descriptiva del català. Barcelona: Institut d'Estudis Catalans.

Rosselló, V. M. 2004. Toponímia, geografia i cartografia. València: PUV.

Rubio Garcia, L. 1981. Del latín al castellano en las escrituras reales. Murcia: Universidad de Murcia. 
Salicrú i Lluch, R. 1999. Documents per a la història de Granada del regnat d'Alfons el Magnànim (1416-1458). Barcelona: CSIC.

Sanchis Guarner, M. 1992. Els pobles valencians parlen els uns dels altres. Castelló de la Plana: Fundació Caixa Castelló.

Sanchis Sivera, J. 1922. Nomenclátor geográfico-eclesiástico de los pueblos de la diócesis de Valencia. València: Miguel Gimeno.

Sansano, G. 2000. Romans nou y curiós sobre un pleyt de un pollastre / que se li perdé a don Salvador Mas, natural de Elig... (1776). Un col·loqui il-licità setcentista. Estudi i edició. A Mas i Miralles, J.; Miralles i Monserrat, J. \& Rosselló i Bover, P. (ed.) Actes de l'Onzè Col-loqui Internacional de Llengua i Literatura Catalanes III. Barcelona: PAM, 279-307.

Schmid, B. 1988. Les "traduccions valencianes" del Blanquerna (València 1521) i de la Scala Dei (Barcelona 1523). Estudi lingüístic. Barcelona: Curial/PAM.

Serra i Fortuño, V. P. 1995. Malnoms i dites. Castelló de la Plana: Excm. Ajuntament de Castelló de la Plana.

Tolosa, Ll.; Company, X. \& Aliaga, J. (ed.). 2011. Documents de la pintura valenciana medieval i moderna III. València: Universitat de València.

Tormo, J. 1997. Origen dels modismes antroponímics alcoians. A Casanova, E. (ed.) IV Col-loqui d'Onomàstica Valenciana. Ontinyent: Denes, 11731197.

Veny, J. 2011. Petit Atles Lingüistic del Domini Català 3. Barcelona: IEC. 
